\title{
PASADO Y FUTURO DEL ESTADO DE BIENESTAR: REFLEXIONES DESDE UNA ERA POSTCOVID
}

\author{
The welfare state's past and future: reflections from a post-covid era
}

María Alexandra Díaz Mordillo*

Cuerpo Superior de técnicos de la administración de Seguridad Social, España

\section{RESUMEN}

La importancia del Estado de Bienestar radica en su capacidad de protección de los riesgos sociales presentes y futuros que amenazan a los ciudadanos a pesar de la bonanza económica. Esta protección se articula a través de un complejo sistema de intervenciones normativas estatales. El pilar fundamental del Estado de Bienestar es la Seguridad Social, tanto por el número de beneficiarios protegidos como por los instrumentos de cobertura. La acción protectora es fruto del devenir histórico, sobre todo de las actuaciones realizadas durante aquellas etapas caracterizadas por alguna crisis económica, social o sanitaria.

El Estado de Bienestar en general y el Sistema de Seguridad Social, en particular, se enfrentan a una serie de retos sobre los que resulta necesario realizar una profunda reflexión, más allá de las consecuencias provocadas por la crisis sanitaria del SARS-Cov-2.

Palabras clave: Estado de Bienestar, Seguridad Social, Pacto de Toledo, SARS-CoV-2.

\section{ABSTRACT}

The importance of the Welfare State lies in its ability to protect from present and future social risks that threaten citizens despite the economic boom. This protection is articulated through a complex system of state regulatory interventions. The fundamental pillar of the Welfare State is Social Security, both for the number of protected beneficiaries and for the instruments of coverage. The protective action is the result of historical evolution, especially of the actions carried out during those stages characterized by some economic, social or health crisis.

The Welfare State in general and the Social Security System, in particular, face a series of challenges on which it is necessary to carry out a deep reflection. Beyond the consequences caused by the SARS-Cov-2 health crisis.

Keywords: Welfare State, Social Security, Toledo Pact, SARS-CoV-2.

\footnotetext{
* Correspondencia a: María Alexandra Díaz Mordillo. Avenida de España, núm. 14, Cáceres, España. — maria-alexandra.diaz@ seg-social.es — https: //orcid.org/0000-0001-8619-3592

Cómo citar: Díaz Mordillo, María Alexandra. (2021). «Pasado y futuro del Estado de Bienestar: reflexiones desde una era postcovid»; Lan Harremanak, 46, 33-59. (https: //doi.org/10.1387/lan-harremanak.23138).
}

Recibido: 22 octubre, 2021; aceptado: 17 noviembre, 2021.

ISSN 1575-7048 - elSSN 2444-5819 / (C) 2021 UPV/EHU

(c) (i) Esta obra está bajo una licencia

Creative Commons Atribución 4.0 Internacional 


\section{El Estado de Bienestar como concepto}

Desde que Beveridge acuñara el término en $1942^{1}$, tradicionalmente se define el Estado de Bienestar como aquel modelo o propuesta política tendente a garantizar la redistribución de recursos y el cumplimiento de los derechos sociales de la totalidad de los habitantes de un país. El Estado que legisla en materia social, en el sentido de aquel que a finales del siglo xIx reacciona frente a los cambios que trajo consigo la revolución industrial y que supuso una ruptura con la concepción imperante hasta el momento, ha tenido diferentes denominaciones: Welfare State anglosajón, État-providence francés, Socialstaat alemán, o incluso las políticas del New Deal de Franklin Roosevelt en Estados Unidos (Menéndez Sebastián, 2014).

Todos estos modelos, aunque con diferentes herramientas, persiguen objetivos comunes: seguridad económica, seguridad social, reducción de la desigualdad y lucha contra la pobreza, que protegerán frente a determinadas contingencias a los ciudadanos o residentes de un país (Muñoz del Bustillo, 2019: 15).

«Es tanto lo que se ha escrito sobre el Estado de Bienestar que parece difícil añadir algo nuevo" (Escolano, 2019: 25). Se trata de un término abstracto que define procesos sociales y políticos muy complejos que adquieren diferente dimensión si tenemos en cuenta la realidad política, social, económica o cultural sobre la que se asientan.

Los tres ejes fundamentales creados por Beveridge para el establecimiento del Estado de Bienestar en Gran Bretańa giraban en torno a la vivienda familiar, salud pública y el empleo. Hoy en día, los instrumentos utilizados para alcanzar estos objetivos se han diversificado sobrepasando las tres funciones originales y alcanzando actuaciones de mayor complejidad. Como medidas más ambiciosas a destacar: el establecimiento de un completo sistema de prestaciones económicas de Seguridad Social que permita la transferencia social de fondos estatales de una forma equitativa; la prestación de servicios públicos básicos y de carácter general (sanidad, educación...) o el establecimiento de programas específicos de rentas básicas universales destinadas a paliar situaciones de necesidad extrema. En España y gracias al modelo social y democrático promulgado por la Constitución ${ }^{2}$, el Estado de Bienestar se sustenta sobre tres pilares fundamentales: «educación, pensiones y sanidad, al que se añade por algunos, últimamente, el de las prestaciones ligadas a las personas en situación de dependencia» (López Jiménez, 2011: 71).

\footnotetext{
${ }^{1}$ Informe Beveridge o Beveridge Report, publicado en 1942 con el título original Social Insurance and Allied Services).

2 Artículo 1 de la Constitución Española publicada en BOE número 311, de 29 de diciembre de 1978.
} 
En resumen, la importancia del Estado de Bienestar radica en proteger los riesgos sociales presentes o futuros que pueden llegar a amenazar a los ciudadanos de un determinado país y que no dejarán de generarse por muy bien que funcionen los recursos económicos de los que se dispone. Estas actuaciones se fundamentan en intervenciones normativas de profundo calado social.

Si atendemos al nivel de protección dispensada y al cuantioso número de beneficiarios, puede afirmarse, como ya lo hace la Comisión del Pacto de Toledo en su Recomendación 0, que los sistemas de Seguridad Social constituyen el eje central de las políticas de bienestar social en los países desarrollados, sobre todo los europeos. Estas políticas están dirigidas a mantener y mejorar el nivel de vida de los ciudadanos evitando situaciones de necesidad y marginación ${ }^{3}$.

Dentro del Sistema de Seguridad Social, serán las pensiones y prestaciones los instrumentos que permitan la consolidación de ese ansiado bienestar.

\section{Las etapas de crisis y su influencia tanto en el Estado de Bienestar como en la acción protectora dispensada por el sistema de Seguridad Social}

\subsection{El análisis histórico como punto de partida}

El Estado de Bienestar es el efecto de un proceso lento de germinación de políticas sociales que trata de dar respuesta a las necesidades de una sociedad en continua evolución. La Seguridad Social es el resultado del devenir histórico y se modula teniendo en cuenta las demandas de la sociedad y las necesidades económicas para su mantenimiento ${ }^{4}$. No es posible comprender las tendencias futuras en las que desembocará el Sistema sin realizar un análisis de su formación histórica (Monereo Pérez, 2019: 21).

Al igual que el resto de Europa, la Seguridad Social española, como pilar fundamental de su Estado de Bienestar, se ha adaptado a las necesidades de una sociedad cada vez más industrializada y con mayores necesidades. Los cambios más importantes en el diseño de políticas sociales han estado ligados a situaciones de emergencia. Una vez superada la situación excepcional, es práctica habitual que estas medidas de urgencia permanezcan y se consoliden dentro de la acción protectora. En ocasiones no parece tenerse en cuenta que, una vez finali-

\footnotetext{
3 Recomendación 0 Pacto de Toledo en su versión de 2020.

4 Subdirección General de Ordenación y Asistencia Jurídica del Instituto Nacional de la Seguridad Social (2018) El sistema español de la Seguridad Social. Antecedentes y Modelo Actual, Madrid: MEYSS p. 6.
} 
zada la crisis que motivó su creación, puede que ya no resulten adecuadas e incluso pudieran causar efectos adversos o duplicidades.

El primitivo «Estado Asistencial» que desvinculaba la protección social del Estado y la encomendaba a la beneficencia privada, se ve superado por las necesidades del creciente desarrollo industrial (Moreno Preciado, 2012). El movimiento obrero, de forma mutualista y fuera de la tutela estatal, instauró una protección propia de reacción frente a la creciente ola de accidentes laborales. En un momento posterior, el Estado decide intervenir en la protección humanitaria de los trabajadores creando los seguros sociales obligatorios. Se inicia así la etapa precursora del actual sistema de Seguridad Social encuadrada dentro del denominado «Estado Providencia» y caracterizada por una protección de carácter contributivo, eminentemente laboral. Este tipo de protección había nacido en la Alemania conservadora del siglo xix, experimentando su desarrollo definitivo en la época de Bismarck ${ }^{5}$. En España destacan la Ley de Accidentes de Trabajo de 1900, el Retiro Obrero de 1919 o la creación del Instituto Nacional de Previsión en 1908, encargado de su gestión.

El establecimiento de una Dictadura en España (1939-1975), afectó al «Estado Providencia» de manera especial. El Régimen Franquista se hizo responsable del auxilio social y los seguros profesionales, incrementando el gasto público (aunque de forma moderada si lo comparamos con el resto de las democracias europeas) y articulando jurídicamente los principios de un sistema social que perdura hasta hoy ${ }^{6}$.

El «Estado Providencia» converge en el Estado de Bienestar, destinado a la provisión de una protección social para todos los ciudadanos, con carácter universal, sin tener en cuenta ni sus ingresos ni su condición social. Este modelo eclosiona al final de la II Guerra Mundial, impulsado por la necesidad de mantener el consumo a fin de asegurar el equilibrio y la expansión económica. En España, hubo que esperar hasta el establecimiento de la democracia en la década de los 70. Con la Constitución Española y los conocidos como Pactos de la Moncloa de 19777, el Estado se encarga de cubrir los riesgos de carácter universal, así como de suministrar los bienes preferentes como educación o sanidad (Pons Pons, 2020: 270). La Seguridad Social vive una etapa de consolidación

5 Mensaje al Reichstag, 17 de noviembre 1881.

6 Ley 193/1963, de 28 de diciembre, sobre Bases de la Seguridad Social, publicada en BOE número 312, de 30 de diciembre de 1963, pp. 18181-18190 y sus textos articulados de 1966 y 1974. Ley 24/1972, de 21 de junio, de financiación y perfeccionamiento de la acción protectora del Régimen General de la Seguridad Social, publicada en BOE número 149, de 22 de junio de 1972, pp. 11174-11177. Real Decreto-ley 36/1978, de 16 de noviembre, sobre gestión institucional de la Seguridad Social, la salud y el empleo, publicado en BOE número 276, de 18 de noviembre de 1978, pp. 26246-26249.

7 https://www.mpr.gob.es/servicios2/publicaciones/vol17/ 
marcada por importantes medidas de reordenación y racionalización de la acción protectora, el establecimiento definitivo de la estructura organizativa que permite dispensar correctamente los servicios, consagrar el modelo constitucional de Seguridad Social del artículo $41^{8}$ y extender de manera universal su ámbito subjetivo basado en la solidaridad.

Resultó imprescindible para esta consolidación del Estado de Bienestar el afianzamiento de las instituciones democráticas unido al crecimiento económico, que permitió alcanzar unos niveles de renta y ahorro mediante los que el Estado pudo establecer sistemas fiscales más justos y eficientes que soportaran los gastos de los servicios sociales demandados por los ciudadanos. El nacimiento de un gobierno democrático influyó directamente en la implantación de un moderno sistema de Seguridad Social en España.

\subsection{Las épocas de crisis y su carácter modelador}

Durante los ańos 80 del pasado siglo, el sistema de protección se enfrenta a un momento delicado caracterizado por una etapa posindustrial en la que el desempleo aumenta peligrosamente. Los empresarios utilizan fórmulas de contratación temporal adaptadas a sus propias necesidades productivas frente a las que se responde con una fuerte oposición sindical. No obstante, el sistema de protección por desempleo acaba adaptándose a la situación, naciendo así las prestaciones de carácter asistencial ${ }^{9}$. El país presenta un fuerte déficit en las arcas del Estado que dificulta la incorporación a la Unión Europea. Esta situación propicia la publicación de la Ley 26/1985, de 31 de julio, de medidas urgentes para la racionalización de la estructura y de la acción protectora de la Seguridad Social que introduce en el sistema cambios relacionados con la jubilación, la incapacidad permanente (acceso desde una situación de no alta, cálculo de la base reguladora o incremento en el periodo de carencia necesario para causar derecho), redistribución de las prestaciones familiares o el incremento de las pensiones asistenciales.

El final de la década coincide con otra huelga general ${ }^{10}$ a la que el Estado reacciona aumentando nuevamente la protección asistencial. Nacen las pen-

8 Artículo 41. «Los poderes públicos mantendrán un régimen público de Seguridad Social para todos los ciudadanos, que garantice la asistencia y prestaciones sociales suficientes ante situaciones de necesidad, especialmente en caso de desempleo. La asistencia y prestaciones complementarias serán libres».

9 Ley 31/1984, de 2 de agosto, de protección por desempleo, por la que se modifica el título II de la Ley 51/1980, de 8 de octubre, publicada en BOE número 186, de 4 de agosto de 1984, pp. 22725-22731 (hoy derogada) y Reglamento de Protección por Desempleo, aprobado por Real Decreto 625/1985, de 2 de abril (vigente hoy en día en lo que no se oponga a la Ley General de Seguridad Social).

${ }^{10}$ Huelga general de 1988 convocada por CCOO y UGT contra la reforma laboral que continua otra anterior, la de 1985, convocada por CCOO contra la reforma de las pensiones. 
siones no contributivas en su moderna concepción (jubilación e invalidez no contributivas) ${ }^{11}$, y se universaliza la asistencia sanitaria ${ }^{12}$ : nuevos gastos que aumentan el déficit público pero que vienen a completar las reformas básicas iniciadas por la Ley 26/1985 en materia asistencial.

El 6 de abril de 1995 se firma el conocido como Pacto de Toledo que permite rebajar la tensión social acumulada durante estos años. El compromiso de las fuerzas parlamentarias para hacer viable el modelo de Seguridad Social implicaba el establecimiento de una serie de objetivos de consolidación financiera y presupuestaria para los que era necesaria la adopción gradual de medidas que lo adaptaran a la realidad del momento. Con esta finalidad nace la Ley 24/1997, de 15 de julio, de Consolidación y Racionalización del Sistema de Seguridad Social, desde la obligación del Estado a adaptarse a las circunstancias sociales y económicas de cada momento histórico ${ }^{13}$. Se incide nuevamente en la necesidad de separación de fuentes de financiación, ampliación del periodo por el que se determina la base reguladora de la pensión de jubilación, acentuación de la proporcionalidad de los ańos de cotización acreditados por el interesado (en orden a su aplicación a la base reguladora de la pensión de jubilación) o establecimiento de una mayor seguridad jurídica a la hora de calificar una pensión de incapacidad permanente.

Desde entonces, no hemos parado de hablar de diferentes etapas de crisis y de recuperación del Estado de Bienestar que han influido directamente en las medidas sociales adoptadas. Así pues, el final del siglo xx se caracteriza por la contención del gasto público y el endurecimiento de los requisitos de acceso al sistema de pensiones que se consolida con la Ley 24/1997. Se inaugura así un nuevo ciclo caracterizado por la necesidad de recortar gastos del Estado, generalmente sociales, (Luque Balbona, 2021: 175), privatizar empresas públicas para sanear las arcas estatales o debilitar aún más el movimiento sindical flexibilizando el mercado laboral, aduciendo la quiebra fiscal del Estado (Tortosa, 2010: 8). Esta misma tendencia también se aprecia en las reformas de principios del siglo XXI.

Ley 40/2007, de 4 de diciembre, de medidas en materia de Seguridad Social, nace tomando como referencia las prioridades marcadas por el Pacto de Toledo en su renovación parlamentaria de 2003. Trata de afianzar el bienestar

11 Ley 26/1990, de 20 de diciembre, por la que se establecen en la Seguridad Social prestaciones no contributivas, publicada en BOE número 306, de 22 de diciembre de 1990, pp. 38246-38251.

12 La Ley 14/1986, de 25 de abril, General de Sanidad, regula todas las acciones que permiten hacer efectivo el derecho a la protección de la salud reconocido en el artículo 43 y concordantes de la Constitución Espańola, establece los principios y criterios sustantivos que han permitido configurar el Sistema Nacional de Salud, como son el carácter público y la universalidad del sistema. Social.

13 Preámbulo de la Ley 24/1997 de Consolidación y Racionalización del Sistema de Seguridad 
del conjunto de los ciudadanos mediante el mantenimiento y refuerzo de determinados principios básicos como la solidaridad y extensión de la acción protectora. Se intensifica la contributividad del sistema, avanzando hacia una mayor proporcionalidad entre las cotizaciones realizadas y las prestaciones obtenidas, evitando situaciones de falta de equidad. Las nuevas realidades familiares, que sobre todo afectan a la pensión de viudedad (parejas de hecho, separaciones o divorcios), obligan a que el sistema se modernice para abordarlas.

Durante la profunda crisis económica acontecida en la primera década del siglo, surge el Real Decreto-ley 8/2010, de 20 de mayo, por el que se adoptan medidas extraordinarias para la reducción del déficit público. Entre las medidas adoptadas, destaca la suspensión de la revalorización de pensiones dinamitando el mandato constitucional del artículo 50.

Esta senda de austeridad continúa con la Ley 27/2011, de 1 de agosto, sobre actualización, adecuación y modernización del sistema de Seguridad Social que, justificándose en la tendencia demográfica y su incidencia en la tasa de dependencia de las pensiones futuras y en la progresiva disminución del periodo de actividad laboral, diseña una de las reformas más ambiciosas de los últimos tiempos. Esta ley tiene como finalidad la de llevar al ordenamiento de la Seguridad Social los compromisos recogidos en el Acuerdo social y económico suscrito el 2 de febrero de 2011, entre el Gobierno del momento y los interlocutores sociales, así como incorporar algunas de las recomendaciones reflejadas en la nueva reformulación del Pacto de Toledo en su versión de ese mismo año. Con un periodo transitorio bastante amplio, se realiza un cambio sustancial tanto en la edad de acceso a la pensión de jubilación, como del periodo necesario para acceder al cien por ciento de esta. Además, se modifica el periodo de cálculo de la base reguladora o los requisitos de acceso para la jubilación parcial ${ }^{14}$.

Por tanto, puede afirmarse que la acción protectora del sistema se ha venido modulando en función de situaciones de necesidad histórica y que estos cambios, con carácter general, permanecen incluso una vez superado el momento de tensión que los motivó. A pesar de que muchas de estas reformas se han basado en sistemas de austeridad, resulta debate cíclico el de los economistas que, desde hace dos décadas, advierten que no podrá sostenerse en el tiempo un sistema de protección con unos gastos tan elevados (Sada, 2001: 46). Se incide en la necesidad de elegir qué gastos pueden ser asumidos y a cuáles puede renunciarse, partiendo de la idea de que los recursos son limitados (Farge Collazo, 2007: 53). Por otro lado, los sistemas de protección son flexibles, esta capacidad de cambio facilita que puedan adaptarse a las nuevas realidades sociales, a la vez que les per-

\footnotetext{
14 Se complementa con Real Decreto-ley 5/2013, de 15 de marzo, de medidas para favorecer la continuidad de la vida laboral de los trabajadores de mayor edad y promover el envejecimiento activo. Publicado en BOE número 65, de 16 de marzo de 2013, pp. 21441-21474.
} 
mite consolidarse por el propio paso del tiempo. ¿Será suficiente esta capacidad de adaptación para garantizar su supervivencia?

\section{La llegada del virus SARS-CoV-2 y los desafíos sociales de una época marcada por la pandemia}

\subsection{Una pandemia mundial}

El 7 de enero de 2020 China identifica el agente causante de un brote de neumonía de etiología desconocida como un nuevo tipo de coronavirus denominado SARS-CoV-2. Desde ese momento, el mundo convulsiona hacia una serie de acontecimientos relacionados con la salud pública que inciden de manera abrupta en la sanidad, sociedad o economía a nivel mundial (Monereo Pérez, 2020: 170). España no es una excepción. Se ponen en marcha un sinfín de medidas destinadas a contener lo que ya se percibe como un inminente peligro mundial. Los países entienden rápidamente que nos encontramos ante una situación grave, inusual o inesperada con efectos para la salud pública que irán más allá de las fronteras del Estado afectado y que probablemente necesitarán una acción internacional inmediata que no se hace esperar (Díaz Mordillo, 2021).

La enfermedad se propaga rápidamente, provocando tanto situaciones incapacitantes temporales de diferente gravedad como la muerte de los infectados. Por este motivo, durante el mes de febrero de 2020 y principios de marzo se refuerzan las medidas de prevención y contención en toda Europa. Estas medidas implican restricciones en los desplazamientos, cuarentenas o cierre de locales de ocio, que inciden violentamente en la economía nacional. En materia de Seguridad Social, es el momento de establecer mecanismos que vengan a suplir los salarios dejados de percibir (como las exoneraciones en las cotizaciones sociales, los aplazamientos o las prestaciones por cese de actividad de los trabajadores autónomos), el establecimiento de rentas especiales que sirvan para paliar la necesidad de los colectivos más vulnerables (como la puesta en marcha del Ingreso Mínimo Vital) o la adaptación del sistema a las nuevas situaciones de necesidad protegible, no identificadas con anterioridad (como la incapacidad temporal para las situaciones de cuarentena preventiva en personas no contagiadas).

Una vez más, el sistema se reinventa para acoplarse al momento temporal y a las necesidades de la población, acudiendo al propio artículo 42 del Texto Refundido de la Ley General de la Seguridad Social (TRLGSS) ${ }^{15}$ que reconoce la

15 Real Decreto Legislativo 8/2015, de 30 de octubre, por el que se aprueba el texto refundido de la Ley General de la Seguridad Social. Publicado en BOE número 261, de 31 de octubre de 2015, pp. 103291-103519. 
Seguridad Social como algo dinámico con capacidad para adaptarse a las contingencias y situaciones especiales que reglamentariamente se determinen mediante Real Decreto a propuesta del Ministerio Competente. Algunas medidas han desaparecido a la vez que la circunstancia que protegían, otras mantienen su carácter temporal y el resto se han incorporado definitivamente al sistema. Como ejemplos más llamativos, destacan los siguientes:

\subsection{Medidas en materia de incapacidad temporal}

Los cierres de localidades, los confinamientos domiciliarios en personas no enfermas (y que, por tanto, no requieren de tratamiento médico) (Aragón Gómez, 2020: 6) o el alto índice de contagios, sobre todo en personal sanitario, obliga al sistema de protección a adaptarse, acogiéndose a una serie de ficciones jurídicas que han servido para proteger a los trabajadores afectados por el SARS$\mathrm{CoV}-2$ en sus relaciones laborales.

Se opta por usar de manera extraordinaria la prestación de incapacidad temporal como medida de salud pública, reforzando su importe al considerarla derivada de accidente de trabajo en aquellos trabajadores a los que no resultaba posible aplicar directamente lo dispuesto en el artículo 156 del TRLGSS. También se convierte en una herramienta preventiva para los casos de aislamiento y cuarentena, así como los cierres perimetrales de diferentes partes del territorio. Por último, en atención al personal sanitario y sociosanitario, objetivo vulnerable por su alto índice de contagios (presumiblemente durante el desempeño de su actividad laboral), se ha modulado la contingencia y protección prestacional de sus procesos Covid-19 hasta alcanzar una consideración exclusivamente profesional; aunque con determinados condicionantes.

La dificultad de establecer un nexo causal contagio/trabajo en medio de una pandemia mundial, ha provocado una concatenación jurídica de carácter extraordinario. El hecho de que la enfermedad termine atacando a todas o la mayoría de las personas, sean o no trabajadoras, dificulta establecer que el contagio se ha producido como consecuencia directa o indirecta del trabajo habitual, sobre todo cuando la intensidad en el ritmo de contagios es mayor. La protección reforzada nacía con el Real Decreto-Ley 6/2020, de 10 de marzo, por el que se adoptan determinadas medidas urgentes en el ámbito económico y para la protección de la salud pública, cuyo artículo quinto introduce por primera vez y de manera excepcional, la consideración como situación asimilada a accidente de trabajo, a los exclusivos efectos de la prestación de incapacidad temporal, de aquellos periodos de aislamiento o contagio de las personas trabajadoras como consecuencia del virus.

En el momento en que el Gobierno, haciendo uso del artículo 116 de la Constitución española, aprueba el Real Decreto 463/2020, por el que se declaró el estado de alarma para la gestión de la situación de emergencia sanita- 
ria ocasionada por la Covid-19 ${ }^{16}$, con medidas para proteger la salud y seguridad de la ciudadanía, contener la propagación de la enfermedad y reforzar el Sistema Nacional de Salud que incluían los cierres perimetrales de municipios y la limitación de la libertad de circulación, es necesario diseñar un nuevo sistema de protección para aquellos trabajadores que tienen imposibilidad de acudir a su puesto de trabajo por estos motivos ${ }^{17}$. El Real Decreto-ley 13/2020, de 7 de abril, por el que se adoptan determinadas medidas urgentes en materia de empleo agrario, en su disposición final primera, modifica el artículo quinto del Real Decreto-Ley 6/2020, introduciendo estas restricciones como situación asimilada al accidente de trabajo a los exclusivos efectos de la prestación económica de incapacidad temporal, con el mismo objetivo general de contribuir a la protección de la salud pública.

Por otro lado, los trabajadores sanitarios y sociosanitarios demandaban una protección especial ante lo que se considera una enfermedad profesional propia de su actividad laboral (Fernández Avilés, 2020). Se publica entonces el Real Decreto-ley 19/2020, de 26 de mayo, por el que se adoptan medidas complementarias en materia agraria, científica, económica, de empleo y Seguridad Social y tributarias para paliar los efectos del SARS-CoV-2. El artículo 9 considera, de manera específica, contingencia profesional derivada de accidente de trabajo, los contagios padecidos por el personal que presta servicio en centros sanitarios o sociosanitarios durante el estado de alarma. Es la primera vez en esta pandemia que se individualiza la causalidad entre la contingencia vírica y el trabajo que se desarrolla, referido a un colectivo concreto (al resto de trabajadores se les aplica el Real Decreto-ley 6/2020). La protección se refuerza con el Real Decreto-ley 3/2021, de 2 de febrero, por el que se adoptan medidas para la reducción de la brecha de género y otras materias en los ámbitos de la Seguridad Social y económico, cuyo artículo 6 considera que este personal, cuando resulte infectado por SARS-Cov2, tendrá las mismas prestaciones que el sistema otorga a aquellas personas que se ven afectadas por una enfermedad profesional, previa emisión del correspondiente informe del servicio de prevención en el que se haga constar que, en el ejercicio de su profesión ha estado expuesto al virus por la prestación de servicios. De nuevo se utiliza el artificio normativo de excepción (se reitera este carácter, "dando una respuesta excepcional a una situación excepcional») para crear una ficción protectora, no realizándose la plena inclusión del coronavirus en el cuadro de enfermedades profesionales (Martínez Barroso, 2021) puesto que la contingencia

16 Publicado en BOE número 67, de 14 de marzo de 2020, pp. 25390-25400.

17 Previamente, el Real Decreto-Ley 9/2020, de 29 de marzo, regulaba un permiso retribuido recuperable para las personas trabajadoras por cuenta ajena que no presten servicios esenciales, con el fin de reducir la movilidad de la población en el contexto de la lucha contra el COVID-19. 
causante, en cualquier caso, sigue siendo profesional derivada de accidente de trabajo $^{18}$.

La excepcionalidad y temporalidad de estas medidas (desde el 11 de marzo de 2020, fecha de declaración de la pandemia internacional por la OMS, hasta el levantamiento de todas las medidas de prevención adoptadas para hacer frente a la crisis sanitaria ${ }^{19}$ ) se encuentra amparada en la particularidad de la situación protegible, aunque implica desprotección de aquellas situaciones futuras que pudieran derivarse de los procesos Covid- $19^{20}$. Sin ir más lejos, con fecha 30/09/2021 se ha publicado el Criterio de Gestión 25/202121 de la Subdirección General de Ordenación y Asistencia Jurídica del INSS, conforme al informe de la Dirección General de Ordenación de la Seguridad Social, sobre contingencia de la que deriva la prestación económica por incapacidad temporal que traiga causa del padecimiento del «síndrome post Covid-19», llegando a la conclusión de que, si bien la causa original como enfermedad común de la prestación no ha variado, la contraprestación económica ya no se realizará simulando su origen en un accidente de trabajo (el personal sanitario y sociosanitario continuará con su regulación específica). La calificación de la contingencia Covid-19 no es un tema cerrado y podrá variar en función de las resoluciones judiciales (Barrios Baudor, 2020: 284).

\subsection{El Ingreso Mínimo Vital como protección a los colectivos más vulnerables}

El Real Decreto-ley 20/2020, de 29 de mayo, por el que se establece el Ingreso Mínimo Vital (IMV), se configura como el derecho subjetivo a la no pobreza materializado a través de una prestación económica que garantiza un nivel mínimo de renta a quienes se encuentran en situación de vulnerabilidad econó-

18 Véase que la Disposición adicional cuarta de la Ley 10/2021, de 9 de julio, establece que las prestaciones derivadas de las enfermedades contraídas por el virus SARS-Cov-2, se considerarán accidente de trabajo, por entender cumplidos los requisitos del artículo 156.2.e) del TRLGSS. Esta disposición entra en contradicción con el artículo 6 del Real Decreto-ley 3/2021, que estableció que las prestaciones serían las propias de la enfermedad profesional (aunque la contingencia causante sigue siendo el accidente de trabajo). La diferencia sustancial radica en la posibilidad o no de poder atender como profesionales, los fallecimientos más allá de los cinco ańos siguientes al contagio. Ante la imposibilidad de determinar exactamente cuál ha sido la voluntad del legislador (si venir a afianzar lo dispuesto en el RDL 3/2021, ya que no lo deroga expresamente o, todo lo contrario), será necesaria una clarificación normativa al respecto.

19 Previsión inicialmente dispuesta para el estado de alarma y posteriormente prorrogada hasta el final de la crisis sanitaria (RD-L 28/2020, de 22 de septiembre).

20 No se consideran situación derivada de accidente de trabajo los efectos adversos provocados por la vacunación o aquellos periodos de cuarentena en un país extranjero donde se exija el aislamiento tras la entrada en el mismo. Por el contrario, sí que se equiparan a los supuestos de aislamiento por contacto estrecho con un positivo por contagio, aquellos periodos de cuarentena obligatorio establecido tras el retorno a España de las personas que han viajado a países respecto de los que se ha impuesto dicha obligatoriedad.

21 https://transparencia.gob.es/ 
mica, garantizando la mejora de oportunidades reales de inclusión social y laboral de las personas beneficiarias (Díaz Mordillo, 2020). La prestación nace después de muchos años de austeridad social en los que la tendencia general había sido precisamente la contraria (Pérez del Prado, 2020: 389): adelgazar la acción protectora hasta centrarla en un sistema de mínimos.

El Ingreso Mínimo Vital acelera su puesta en marcha debido a la crisis sanitaria $^{22}$, aunque las Comunidades Autónomas ya había diseñado una red de protección propia. En el País Vasco se pone en marcha en 1989 el primer programa autonómico de rentas mínimas que culmina con la instauración, a mediados de los años noventa del pasado siglo, de una prestación asistencial propia en cada una de las Comunidades Autónomas de España. Estas rentas han supuesto el último recurso de la red de protección contra la pobreza, aunque se trata de modelos muy diferentes entre sí, con variaciones sustanciales en cuanto a su diseño, grado de cobertura y nivel de protección ${ }^{23}$.

A pesar de estas disfunciones, se trata de un sistema protector que ha venido funcionando con efectividad a lo largo del tiempo y que se engloba dentro de la propia esfera competencial autonómica. La situación de emergencia económica provocada por la crisis sanitaria y el estado de alarma declarado por el Real Decreto 463/2020, aceleraron la creación de una prestación de ámbito nacional configurada como una prestación de base, compatible con estas rentas mínimas territoriales, que ha ocasionado un gran reto de coordinación administrativa (Gala Durán, 2002, 155).

El Ingreso Mínimo Vital ha servido para dar solución a la situación de pobreza extrema de un total de 337.000 hogares, de los que forman parte unos 800.000 beneficiarios $^{24}$, siendo un claro ejemplo de adaptación de la acción protectora al sistema de Seguridad Social con vocación de futuro puesto que no se ha estructurado como un sistema temporal, sino como un sistema estructural dentro de la acción protectora estatal (Sempere Navarro, 2021). El riesgo de pobreza se ha visto incrementado por la pandemia, eso sí, pero permanecerá acechando a la sociedad una vez superada la misma (Barcelón Cobedo, 2020: 183), siendo el desempleo la causa más habitual. No obstante, los múltiples fallos de diseño en la configuración normativa inicial y las cuestiones pendientes de desarrollo reglamentario hacen que, después de año y medio de su creación, sea absolutamente necesario abordar su reorganización más inmediata (Monereo Pérez, 2020: 273). El Proyecto de Ley por la que se establece el ingreso mínimo vital (procedente del Real Decreto-ley 20/2020, de 29 de mayo), que actual-

22 En 2017, el fundamento número 14 del Pilar Europeo de derechos sociales ya resaltaba la necesidad de una renta mínima que garantice una vida digna.

23 AIRef (2019): Los programas de Rentas Minimas en España. Madrid AIRef. Disponible en https://www.airef.es

24 Nota de prensa del viernes 1 de octubre de 2021. https://n9.cl/o588b 
mente se debate en el Congreso ${ }^{25}$, está destinado a corregir las deficiencias del texto original que, a pesar de las reformas posteriores ${ }^{26}$, aún no han sido solventadas: itinerarios de inserción laboral, compatibilidad del trabajo con el Ingreso Mínimo Vital como ya hizo la Ley 8/2005, de 6 de junio, para compatibilizar las pensiones de invalidez en su modalidad no contributiva con el trabajo remunerado (Sala Franco, 2020) ${ }^{27}$, cómputo permanente de ingresos del año en curso en lugar del anterior o una mayor agilidad en su tramitación.

\subsection{Medidas extraordinarias para combatir el desempleo: expedientes temporales de regulación de empleo (ERTE), exoneraciones de cuotas o prestaciones por cese de actividad RETA}

El ańo 2020 puede ser clasificado como una época cambiante y poco predecible. El derecho a una ocupación efectiva y un trabajo remunerado entraba en conflicto permanente con el derecho a la salud de los trabajadores en particular y de la población general. Por este motivo, además del uso de la prestación de incapacidad temporal como medida de salud pública, era necesario afrontar las consecuencias que las medidas de contención del virus habían provocado en la actividad económica. El Real Decreto-ley 8/2020, de 17 de marzo, de medidas urgentes extraordinarias para hacer frente al impacto económico y social del COVID-19, adopta una batería de medidas que proporcionan la necesaria flexibilidad para el ajuste temporal de las empresas con el fin de favorecer el mantenimiento del empleo y reforzar la protección de los trabajadores directamente afectados. Por un lado, se produce la flexibilización de los mecanismos de ajuste temporal de la actividad de las empresas para evitar despidos (ERTE), además de las exoneraciones en las cuotas empresariales a la Seguridad Social, que persiguen evitar que una situación coyuntural tenga un impacto negativo y se convierta en estructural para la economía (Blasco Lahoz, 2021) ${ }^{28}$. Por otro lado, se establece una prestación económica para los trabajadores afectados, que incluía también como beneficiarios a los trabajadores fijos discontinuos ${ }^{29}$ y a los socios trabajadores de sociedades laborales y de cooperativa de trabajo aso-

25 https://www.congreso.es/public_oficiales/L14/CONG/BOCG/A/BOCG-14-A-25-2.PDF

26 Real Decreto-ley 25/2020 de 3 de julio, de medidas urgentes para apoyar la reactivación económica y el empleo; RD-ley 28/2020, de 22 de septiembre, de trabajo a distancia; RD-ley 30/2020, de 29 de septiembre, de medidas sociales en defensa del empleo; RD-ley 3/2021, de 2 de febrero, por el que se adoptan medidas para la reducción de la brecha de género y otras materias en los ámbitos de la Seguridad Social y económico o la Ley 10/2021, de 9 de julio, de trabajo a distancia.

27 Desde la página 120 en adelante se realiza un pormenorizado análisis sobre los incentivos al empleo contenidos en la regulación del IMV con el fin de evitar las denominadas «trampas de pobreza».

${ }^{28}$ De obligada lectura para entender el contexto de protección del desempleo durante la pandemia.

29 El Real Decreto-ley 15/2020, de 21 de abril, de medidas urgentes complementarias para apoyar la economía y el empleo, completa la protección a este colectivo. 
ciado que tuvieran previsto cotizar por la prestación de desempleo (Arenas Gómez, 2020).

El ámbito temporal de estas medidas finalizaba el 30 de junio de 2020 con carácter general (31 de diciembre de 2020 para los fijos discontinuos), aunque el propio Real Decreto vinculaba el percibo de las prestaciones a la duración de la situación extraordinaria derivada del Covid-19, afirmación que hacía suponer, a la vista de la situación sanitaria, que las medidas se prolongarían más allá de las fechas iniciales.

El Real Decreto-ley 8/2020 también protegía a los trabajadores autónomos, incluidos los trabajadores del mar por cuenta propia, que habían visto suspendida su actividad, introduciendo una prestación económica sustitutiva de ingresos y con vigencia limitada hasta la finalización del Estado de Alarma (el Real Decreto-ley 19/2020, de 26 de mayo, por el que se adoptan medidas complementarias en materia agraria, científica, económica, de empleo y Seguridad Social y tributarias para paliar los efectos del Covid-19, aclaraba que alcanzaría hasta el último día del mes en que finalizara el Estado de Alarma), (González Martínez, 2020).

El Real Decreto-ley 11/2020, de 31 de marzo, por el que se adoptan medidas urgentes complementarias en el ámbito social y económico para hacer frente al Covid-19, extiende la protección por desempleo al colectivo de trabajadores del hogar que vieron extinguidos o suspendidos sus contratos de trabajo durante el Estado de Alarma. Hay que destacar como novedoso que este colectivo no tiene incluido el desempleo dentro de su acción protectora.

Pero la protección extraordinaria abarca también a otros trabajadores: el mismo Real Decreto-ley 11/2020 otorga un subsidio extraordinario al colectivo de trabajadores temporales con finalización de contrato, debido a la dificultad añadida de encontrar un nuevo empleo durante la pandemia. Por su parte, el Real Decreto-ley 17/2020, de 5 de mayo, por el que se aprueban medidas de apoyo al sector cultural y de carácter tributario para hacer frente al impacto económico y social del Covid-19 reconoció el acceso a la prestación de desempleo de los artistas, también con carácter extraordinario (Beltrán de Heredia Ruiz, 2020).

La persistencia de la crisis sanitaria y económica ha ocasionado la prórroga de las medidas. Hoy en día, el Real Decreto-ley 18/2021, de 28 de septiembre, de medidas urgentes para la protección del empleo, la recuperación económica y la mejora del mercado de trabajo ${ }^{30}$, mantiene la protección dispensada por los ERTE y las prestaciones de cese de actividad de trabajadores autónomos hasta el 28 de febrero de 2022, fecha en la que será necesario revisar su viabilidad. El

30 Publicado en BOE número 233, de 29 de septiembre de 2021, pp. 119345-119382. Cita posterior del preámbulo de esta norma. 
motivo es claro, aunque el nivel de contagios es oscilante, sus consecuencias negativas son apreciables aún para empresas y trabajadores. El carácter incierto de su evolución aconseja mantener la protección ${ }^{31}$.

\subsection{El uso de fraccionamientos y aplazamientos como medida de protección}

El aplazamiento del pago de deudas con la Seguridad Social es un acto administrativo solicitado por el deudor que le autoriza a abonar deudas fraccionadas fuera del plazo reglamentario de ingreso, con el correspondiente devengo de intereses y que permite considerarle, mientras cumpla con los plazos, al corriente de las deudas aplazadas ${ }^{32}$.

Los aplazamientos como medida protectora en situación de necesidad han estado presentes entre las recomendaciones del Pacto de Toledo desde su versión de 2003. Durante la crisis económica de la primera década del siglo xxI fueron imprescindibles como medio de liquidez, pero ha sido precisamente la llegada de la crisis sanitaria actual la que ha puesto de manifiesto la importancia real de este tipo de soluciones. En el año 2020, ante la emergencia sanitaria provocada por el coronavirus Covid-19 y su repercusión en la liquidez de las empresas y de los trabajadores por cuenta propia, aparecen una serie normas que utilizan aplazamientos a un tipo de interés reducido o modulan sus requisitos, y moratorias en el pago de las deudas para beneficiar, junto a las exoneraciones, a aquellos sectores de la actividad económica más golpeados por los cierres y reducciones de actividad.

El primero fue el Real Decreto-Ley 11/2020, de 31 de marzo, por el que se adoptan medidas urgentes complementarias en el ámbito social y económico para hacer frente al Covid-19. Esta norma permitía la posibilidad de realizar moratorias - artículo $34^{33}$ - del pago de las aportaciones empresariales y por conceptos de recaudación conjunta, de seis meses, sin interés, cuyo periodo de devengo estuviera comprendido entre los meses de abril y junio de 2020. También introduce el aplazamiento - artículo 35- en el pago de sus deudas con la Seguridad Social cuyo plazo reglamentario de ingreso tuviera lugar entre los meses de abril y junio de 2020 a un tipo de interés reducido del $0,5 \%{ }^{34}$. Esta modalidad nace con la intención de proteger el tejido productivo y social y facilitar la actividad económica.

31 Preámbulo del Real Decreto-ley 18/2021, de 28 de septiembre.

32 Artículo 23 del TRLGSS y artículos 31-36 del RD 1415/2004, de 11 de junio por el que se aprueba el Reglamento General de Recaudación de la Seguridad Social.

33 La Orden ISM/371/2020, de 24 de abril, viene a desarrollar el artículo 34 del Real Decretoley 11/2020, de 31 de marzo, determinando las actividades económicas que podrán acogerse a ella.

34 Con anterioridad a 2013 y con carácter general, se devengaba interés conforme al interés legal del dinero que se encontraba vigente en cada momento durante la duración del aplazamiento. La disposición adicional quinta uno de la Ley 17/2012, de Presupuestos Generales del Estado para 2013, modifica el artículo 20 del TRLGSS y, a partir del 1 de enero de 2013, el interés que se devenga es conforme al interés de demora vigente en cada momento, actualmente del 3,75\%. 
El RDL 11/2020 se complementa con la Resolución de 6 de abril de 2020 de la Tesorería General de la Seguridad Social, modifica, con efectos del día 9 de abril, la Resolución de 16 de julio de 2004 sobre determinación de funciones en materia de gestión recaudatoria de la Seguridad Social y el art. 33.4.b) del Reglamento general de recaudación de la Seguridad Social para elevar las cuantías de las deudas aplazables por debajo de las cuales no será exigible la constitución de garantías con el fin de facilitar la concesión de estos: la exención se produce cuando el total de la deuda aplazable sea igual o inferior a 150.000 (antes 30.000 euros) o cuando, siendo la deuda aplazable inferior a 250.000 (antes 90.000 euros), se acuerde que se ingrese al menos un tercio de esta última antes de que hayan transcurrido diez días desde la notificación de la concesión y el resto en los dos ańos siguientes.

La Disposición final 43. ${ }^{a}$ de la Ley 11/2020 de 30 de diciembre, de Presupuestos Generales del Estado para 2021, permitía a las empresas y autónomos, siempre que se encontraran al corriente de sus obligaciones y no tuvieran otro aplazamiento en vigor, solicitar moratoria mediante aplazamiento en cuotas cuyo devengo hubiera tenido lugar entre los meses de diciembre de 2020 y febrero de 2021 si son empresas y entre los meses de enero a marzo de 2021 en el caso de trabajadores autónomos. El tipo de interés aplicable volvía a ser el 0,5\% y se facilitaba su presentación electrónica como ya ocurrió en abril. Esta disposición nace bajo el contexto de incertidumbre económica derivado de la pandemia y no resulta extraño que, de continuar la situación sanitaria en términos actuales, asistamos a nuevas prórrogas de estas medidas destinadas a sectores tan castigados como comercio u hostelería. De hecho, ante los daños ocasionado por las erupciones volcánicas en la isla de La Palma, el artículo 10 del Real Decretoley 20/2021, de 5 de octubre, por el que se adoptan medidas urgentes para la reparación de los daños causados, establece, entre otras cuestiones, la concesión de aplazamientos con un interés especialmente reducido para aquellas empresas y trabajadores por cuenta propia de dicha Comunidad Autónoma que hayan sido afectado por la erupción.

\section{El fin de la pandemia y la continuidad de las medidas de urgencia}

Nuevamente, ante una situación de necesidad extrema, han sido las políticas sociales las que han servido para mitigar los efectos de la ralentización de la actividad económica. Gracias a la estabilidad de los ingresos y a las medidas de protección frente a las nuevas amenazas, se ha conseguido amortiguar el impacto de la crisis sobre la pobreza, garantizando así la paz social.

Con todo lo expuesto, podemos clasificar la producción normativa acontecida desde el inicio de la crisis sanitaria como: aquella nacida para el momento 
concreto (que no tendrá un recorrido más allá de la crisis sanitaria) y aquella otra que, con o sin intención de hacerlo, presenta un carácter más permanente a lo largo del tiempo. Los ejemplos de temporalidad de las medidas adoptadas durante la pandemia son inagotables: por un lado, resulta lógico que una situación de necesidad concreta y extraordinaria sea protegida con medidas especiales que se agotarán cuando la necesidad protegible desaparezca. Por otro lado, no cabe duda de que esta temporalidad puede llegar a provocar efectos adversos y situaciones de desigualdad. La prolífica normativa publicada de urgencia durante la crisis sanitaria, aunque con demasiada improvisación en muchos casos (comprensible dentro del contexto histórico), ha cumplido su función vertebradora de protección estatal a pesar de los posibles errores.

La experiencia de años de reformas lleva a pensar que la supervivencia y estabilidad del sistema de protección español están íntimamente relacionadas con la asunción de reformas estructurales, desvinculadas de un momento coyuntural concreto: que sean fruto del debate y consenso (el Real Decreto-ley debe usarse sólo en caso de necesidad), además de estar integradas en un plan de largo alcance, puesto que este tipo de reformas necesita programarse con bastante tiempo de antelación. La deriva errática en la reforma sistemática e improvisada de las pensiones desde los años 80 del pasado siglo, ha demostrado que el legislador ha invertido el mismo tiempo en establecer medidas poco meditadas en materia de jubilación anticipada que, luego, en querer volver atrás para corregir sus decisiones (Monereo Pérez, 2015).

La época de crisis actual no debería ser el factor determinante de la orientación jurídica de las reformas sociales por muy necesarias que sean las medidas adoptadas (Monereo Pérez, 2021: 51). Las reformas llevadas a cabo deben buscar el equilibrio, ya que las medidas tomadas como protección ante un momento de crisis concreto, puede que estén perfectamente armonizadas para esa situación, pero también puede que, a la vez, entren en contradicción con otras medidas anteriores o con el propio sistema de protección a nivel general. Cualquier reforma debe contar con un elevado nivel de acuerdo social y político (un pacto social que vertebre la regeneración de un estado social). Sus costes presupuestarios deben ser estimados, pero también sus implicaciones en términos de equidad y eficiencia (Bandrés Moliné, 2012).

\section{El futuro de la protección social y el Estado de Bienestar}

\subsection{Antiguos problemas, retos nuevos}

Las transformaciones económicas, demográficas y sociales a las que asiste la sociedad actual son de una rapidez vertiginosa, mucho más tras la crisis sanitaria iniciada en 2020. Estos cambios suponen la aparición de nuevos riesgos, no 
previstos en la protección tradicional, que obligan a los Gobiernos a replantearse el sistema en su conjunto. Además, en la práctica, cualquier intervención gubernamental puede afectar directamente sobre el Estado de Bienestar de una u otra forma. También sobre la salud del Sistema de pensiones y prestaciones que configuran el ámbito de protección de la Seguridad Social, íntimamente relacionado con la situación demográfica y la situación financiera estatal. Las pensiones públicas han respondido mejor que las privadas a la crisis sanitaria, aunque ya pesaran sobre ellas dificultades estructurales anteriores, como el creciente desempleo, que hace peligrar la financiación del sistema de reparto (Monereo Pérez, 2021, 54).

Conocidos son los problemas más clásicos como el envejecimiento de la población, las nuevas formas de trabajo, la revolución tecnológica, los modelos de financiación, la globalización, las transiciones verdes o, mucho menos explorado, la descapitalización humana de las Entidades Gestoras y Servicios Comunes de la Seguridad Social que, en un breve espacio de tiempo harán insostenible la gestión de pensiones y prestaciones. Si cualquier cambio en el entorno que afecte a los parámetros con los que está diseñado el modelo de protección pone en grave riesgo la situación financiera del mismo, la crisis sanitaria ha agravado todas las previsiones a largo plazo (Higuerillas Redecillas, 2021: 163).

Si bien es cierto que los problemas más urgentes del sistema de pensiones son de índole económica, no puede obviarse que a largo plazo serán también demográficos (Leguina, 2014: 131). Resulta imprescindible garantizar el equilibrio intergeneracional puesto que la aportación del trabajador sostiene el gasto del pensionista a cambio de que de que sus propios gastos como pensionista sean sufragados por trabajadores futuros. El envejecimiento de la población supone una carga tanto para el sistema de pensiones como para el sistema sanitario, que son los programas sociales más costosos. Las pensiones se perciben en cuantías más altas y durante más tiempo, y el gasto sanitario será mucho más importante cuanto más longevo es el beneficiario que recibe la asistencia. Si el aumento de gastos viene unido con una reducción de ingresos por falta de cotizaciones, el equilibrio se rompe. En una etapa post-pandémica, nuevos problemas afectan a la curva demográfica y pueden intensificar la descompensación generacional: el incremento moderado de la mortalidad, el descenso de la natalidad por la incertidumbre económica y el freno de la inmigración, ocasionado en gran parte por las medidas de contención ${ }^{35}$. Aún es pronto para conocer si el cambio de tendencia observado en 2020 continuará a lo largo del tiempo ya que dependerá en gran medida de la situación sanitaria futura.

La crisis del Covid-19 también ha acelerado la implantación de nuevos modelos productivos basados en la compleja revolución tecnológica que viene a

35 Exceso de mortalidad de 80.203 defunciones en el año 2020, 22.182 niños menos que en 2019 y un descenso en la llegada de inmigrantes del 19,29\%. https://ine.es/covid/covid_salud.htm 
desembocar en un sistema global de financiación, inversión y comercio, que ocasionará la desaparición del trabajador productivo estándar, sobre el que se inspiró el Estado de Bienestar postbélico ${ }^{36}$ (sostenedor masculino de la familia cuya única carga para el Estado de Bienestar era su pase a la jubilación) (Sada, 2001: 47). Las empresas han invertido en tecnología mucho más rápido que antes de la pandemia, movidas por la necesidad de deslocalizar la gestión y de culminar su progresiva independencia del capital humano, mucho más volátil y sujeto a limitaciones de salud pública. La cuarta Revolución Industrial (Revolución industrial 4.0) se ha acelerado y aporta destrucción de trabajos y movilidad de trabajadores a nuevas formas de empleo que se escapan del control jurídico. Los nuevos perfiles laborales ocasionarán riesgos emergentes ligados a las nuevas tecnologías y el teletrabajo, para los que será necesario adaptar la acción protectora (Álvarez Alonso, 2021: 78).

El sistema de recaudación, proporcional a los salarios, está perjudicando a las empresas menos digitalizadas y que presentan un mayor porcentaje de mano de obra en activo. Esto repercute negativamente en la contratación. Por otro lado, la disminución de cotizantes y el importe de las cantidades cotizadas, relacionadas con el salario que se percibe (más contratos temporales y parciales, precariedad, falsos autónomos...), inciden directamente en el modelo de financiación del sistema de Seguridad Social. Resulta necesario acompasar las medidas de protección a la natalidad a la vez que las de fomento de empleo. Además, «el progreso técnico no puede convertirse en desempleo tecnológico» (Muñoz de Bustillo, 2019: 315), pudiéndose tomar medidas como el aumento del salario mínimo interprofesional, complementos salariales o medidas que garanticen la redistribución de riqueza.

Pero si hay un factor que ha provocado la rápida expansión del virus por el planeta, ha sido la globalización. Este fenómeno no deja de ser una fase más en el proceso histórico de expansión del capital (Rodríguez Guerra, 2006: 149). Una creciente globalización implica la convergencia de la economía a un modelo internacional que conlleva el movimiento de trabajadores y sus repercusiones sociales, la deslocalización de la producción y la necesidad de que las empresas amplíen su capacidad de adaptación al nuevo modelo para no perder competitividad. La hiperglobalización actual ha dejado indefensos a los Estados más débiles y, en ellos, a las personas más vulnerables. Los Estados más desarrollados han sido capaces de tejer redes de protección social que han sabido mitigar, al menos en parte, las consecuencias de la crisis mundial (Monereo Pérez, 2020: 172). Aunque un dilema se cierne sobre las sociedades postindustriales contemporáneas, el de acompasar la libertad de circulación, reconocida como un derecho universal básico, y la necesidad de garantizar la seguridad nacional

36 II Guerra Mundial. 
(Moreno Fuentes, 2007: 182), sobre todo en estos momentos de emergencia sanitaria.

Por otro lado, según diferentes teorías, en un mundo caracterizado por la globalización, los países con menor gasto social serían más competitivos que aquellos que presentan un Estado de Bienestar más desarrollado y, por tanto, más difícil de sostener en términos económicos. No obstante, hay autores que defienden precisamente lo contrario (Muñoz de Bustillo, 2019: 194). Los flujos migratorios provocan cierto rechazo en cuanto al riesgo que puede suponer la población migrante para el sistema social de un país. Realmente, no parece que estos movimientos de personas hayan supuesto un riesgo para el Estado de Bienestar del país de acogida, en el sentido de abusar de prestaciones sociales., siendo notoria su contribución al sostenimiento financiero del sistema desde el mundo laboral (Muńoz de Bustillo, 2017: 224).

Por último, la sostenibilidad financiera sigue siendo la mayor preocupación de los expertos y la base sobre la que se fundamentan la mayoría de la legislación sobre acción protectora. El alto nivel de gasto público se financia mediante unos ingresos que no lo cubren en su totalidad, obligando al Estado a recurrir de manera estructural al déficit (Escolano, 2019: 33). El parón en la economía mundial ha provocado un descenso en los ingresos a la vez que ha crecido el gasto social, dos parámetros que han incrementado peligrosamente la presión sobre el sistema. A pesar de las dificultades, el sistema público de reparto es mucho más efectivo que los sistemas privados (que deben ser complementarios, en cualquier caso, nunca alternativos), aunque eso no quiere decir que no necesite ajustes económicos en su diseño, sobre todo en lo que se refiere a la obtención de nuevos ingresos.

\subsection{El desempleo tras la pandemia}

El Covid-19 ha tenido y tendrá, como no podía ser de otra manera, una amplia repercusión en el mercado laboral ${ }^{37}$. La hibernación económica como medida de salud pública, ha ocasionado un descenso en la cantidad de puestos de trabajo que ofrece el mercado (por el cierre de empresas, la proliferación de la economía sumergida o la automatización de tareas) y una disminución de salarios que conllevará un aumento de la demanda de prestaciones sociales, contributivas o no. Estas consecuencias serán mucho más acusadas en aquellos grupos que presentaban mayor vulnerabilidad incluso antes de la crisis sanitaria. La falta de empleo provoca pobreza, pero también lo hace el empleo precario, subempleos temporales y a tiempo parcial que requieren de la ayuda asistencial como complemento. Por otro lado, la dependencia del sistema público de pen-

37 Según datos del INE (encuesta EPA enero 2021), se perdieron en 2020 un total de 1.359.700 puestos de trabajo sin tener en cuenta a los trabajadores en ERTE. 
siones a las cotizaciones sociales ocasionará también la necesidad de buscar nuevas formas de financiación ante un incremento del desempleo.

Las políticas de empleo durante el año 2020 han respondido a lo articulado en la Estrategia Europea de empleo 2020, que se ha unido a la estrategia nacional de Activación para el Empleo 2017-2020, y que han invertido recursos en las prestaciones temporales para trabajadores en ERTE o la protección excepcional para determinados colectivos. Estas medidas, lejos de la austeridad impuesta como solución al colapso financiero de 2008, han garantizado los ingresos de las personas afectadas y han contribuido, en parte, al sostenimiento del sistema. De nuevo, es la acción protectora de la Seguridad Social la que ha servido para rescatar el sistema económico y garantizar la igualdad de oportunidades mediante la redistribución de recursos, demostrando nuevamente cuán equivocadas han sido las políticas de austeridad extrema impuestas desde 2008. A pesar de todo, parece consecuente que se inicie el diseño de un plan de contención para las posibles repercusiones que puede ocasionar el final de los ERTE y prestaciones por cese de actividad, ya que estas medidas de protección están provocando distorsiones optimistas en el cómputo real de la población activa.

De aquí en adelante, los Gobiernos están llamados a revisar y afianzar políticas que garanticen el pleno empleo y la integración de personas con dificultades de inserción y de aquellos colectivos más castigados por la precariedad laboral (jóvenes, mujeres, parados de larga duración, víctimas de violencia de género o personas con discapacidad), acompasadas a la recuperación económica, tal y como recomienda la propia Unión Europea (Monereo Pérez, 2017: 213). También deben contribuir al afianzamiento y modernización del Sistema de Seguridad Social, incluyendo la protección no contributiva, ya que su función ha sido determinante para mantener un equilibrio económico y social durante los meses de mayor incertidumbre. No debe obviarse que los problemas de sostenibilidad financiera son urgentes e inmediatos y requieren de soluciones consensuadas a largo plazo. El Plan de Acción del Pilar Europeo de Derechos Sociales ${ }^{38}$ propone una mayor reflexión sobre los modelos de financiación de la actuación social que permitan formas solidarias de protección entre y dentro de las generaciones.

El sistema debe dar respuesta a las necesidades de una sociedad cada vez más fragmentada y compleja que necesita una renovación o reinvención del Estado Social contemporáneo (Monereo Pérez, 2020) ante los giros inesperados del capitalismo actual.

38 Plan de Acción del Pilar Europeo de Derechos Sociales, disponible en https:/ec.europa.eu/ info/strategy/priorities-2019-2024/economy-works-people/jobs-growth-and-investment/europeanpillar-social-rights/european-pillar-social-rights-action-plan_es (Accedido: 16-10-2021) 


\subsection{El desafío de la gestión. La descapitalización humana de las Entidades Gestoras y Servicios Comunes}

Aunque el debate sobre el sostenimiento del sistema se ha centrado tradicionalmente en las cuestiones expuestas en el epígrafe anterior, existe otra cuestión de suma importancia sobre la que no se está focalizando lo suficiente. La ley de Presupuestos Generales del Estado para el año $2008^{39}$ fue la última en comprometerse a incrementar el número total de plazas de nuevo ingreso para el personal del sector público como máximo, igual al cien por ciento de la tasa de reposición de efectivos. Desde ese momento, la oferta de empleo público se ha visto reducida sistemáticamente, y no ha sido hasta el la Ley de Presupuestos Generales del año $2017^{40}$ (y siguientes) y fruto de la situación de mejora económica general, cuando se ha retomado la idea de acompasar la tasa de reposición a las bajas reales de los trabajadores públicos. Aunque el número de efectivos perdidos no será reemplazable.

Las intervenciones públicas destinadas a producir buenos y numerosos puestos de trabajo, es una responsabilidad estatal poco desarrollada en nuestro país ${ }^{41}$. Por un lado, deben establecerse condiciones favorables para que el sector privado los produzca y, cuando estos no sean suficientes, apoyar mediante la generación de empleo público. El empleo es imprescindible para el mantenimiento del sistema prestacional en constante preocupación por su estabilidad financiera, pero también es necesario y urgente reforzar los cuerpos funcionariales responsables de la gestión y reparto de las pensiones y prestaciones públicas entre los beneficiarios con derecho a ellas.

En particular, las Entidades Gestoras y Servicios comunes de la Seguridad Social también se han visto afectadas por los recortes de personal. De los 31.472 efectivos disponibles en 2002, sólo quedan 20.509 en activo (10.205 del Instituto Nacional de la Seguridad Social y 10.304 de la Tesorería general de la Seguridad Social), con edades medias superiores a los 50 años, siendo los trabajadores de edad inferior tan sólo el 15 por ciento total. Los mayores de 60 años ascienden al 28 por ciento y la franja de edad comprendida entre los 50 y los 59 años, el 57 por ciento ${ }^{42}$.

Las medidas instauradas para paliar la crisis sanitaria iniciada el ańo 2020 no hubieran podido materializarse sin el trabajo y esfuerzo de los trabajadores públicos que, en un corto espacio de tiempo, han sabido adaptarse al trabajo no

\footnotetext{
39 Ley 51/2007, de 26 de diciembre, de Presupuestos Generales del Estado para el año 2008. Publicada en BOE número 310, de 27 de diciembre de 2007, pp. 53286-53409.

${ }^{40}$ Ley 3/2017, de 27 de junio, de Presupuestos Generales del Estado para el año 2017. Publicada en BOE número 153, de 28 de junio de 2017, pp. 53787-54396.

41 OECD (Organización para la Cooperación y el Desarrollo económico) (2013) Government at a Glance 2013. Disponible en www.oecd.org (accedido: 21-10-2021).

42 Datos de julio de 2020 publicados en el Boletín Estadístico del personal al servicio de las Administraciones Públicas. Disponible en https://n9.cl/i1e74 (acceso 16-10-2021).
} 
presencial en unas organizaciones que no estaban preparadas para ello. La transformación digital o la externalización de servicios no son la solución para la fuga de conocimiento que está produciendo pérdidas irreparables en los modelos de gestión, sin tener la seguridad de que gestión privada sea más eficiente que la pública (Torres López, 2010: 15).

La Recomendación Octava del Pacto de Toledo en su versión de $2020^{43}$ ya advertía que para contribuir a la mejora de las funciones que desarrollan las distintas Entidades Gestoras y los Servicios Comunes de la Seguridad social, resulta necesario abordar la urgente necesidad de reforzar la dotación de plantillas mediante un Plan Integral de recuperación y renovación de personal por medio de una cobertura ordenada, paulatina e ininterrumpida del desmesurado número de plazas que han ido quedando vacantes durante las últimas décadas en los diferentes niveles de gestión. Esta pérdida de efectivos, indica la Comisión, puede afectar la atención eficiente, adecuada y ágil que la ciudadanía demanda de la Seguridad Social... pero realmente, ¿̇la gestión no se habrá visto ya afectada en la actualidad?

El Real Decreto-ley 2/2021, de 26 de enero, de refuerzo y consolidación de medidas sociales en defensa del empleo, vino a reconocer la ralentización de la tramitación de los expedientes administrativos durante la situación de pandemia, que empuja a introducir cambios en la competencia territorial de los órganos provinciales para facilitar el reparto de cargas de trabajo entre provincias.

Como era de esperar, resulta indispensable para garantizar el Estado de Bienestar, la intervención directa del Estado a través de su Sector público, garantizando la calidad de los servicios prestados mediante leyes que los regulen y que sirvan para mitigar una posible crisis de legitimidad. Realmente puede afirmarse que resulta imprescindible la dotación inmediata de plantillas ya que estos problemas se están convirtiendo en algo demasiado común. Urge la revisión de la Relación de Puestos de Trabajo con el fin de ordenar el personal de acuerdo con las necesidades reales del servicio y la tan ansiada creación de la Agencia de Seguridad Social que garantice la simplificación, racionalización, economía de costes y eficacia, así como los principios de solidaridad, igualdad y equidad que conforman el sistema.

\section{A modo de reflexión}

1. La importancia del Estado de Bienestar radica en proteger los riesgos sociales presentes y futuros que amenazan a los ciudadanos a pesar de la bonanza

43 Publicado en el Boletín Oficial de las Cortes Generales número 175, con fecha 10 de noviembre de 2020. informe-comision-pacto-toledo-2020.pdf (documentacion.eu). 
económica. Esta protección se articula a través de un complejo sistema de intervenciones normativas estatales, sobre todo en materia de Seguridad Social.

2. Las crisis energéticas de los años 70 o principios de los 90, la crisis económica de la primera década del siglo XXI, el envejecimiento paulatino de la población o la crisis sanitaria provocada por el virus SARS-CoV-2 en 2020, han moldeado la acción protectora. Por un lado, la protección es flexible y adaptable a las circunstancias (esto propicia su consolidación), por otro lado, los recursos que la mantienen son limitados, lo que hace plantearse qué gastos son asumibles y a cuáles es necesario renunciar.

3. Nuevamente, ante una situación de necesidad extrema, han sido las políticas sociales las que han servido para mitigar los efectos de la ralentización de la actividad económica, evitando conflictos sociales. Aunque la experiencia de años pasados nos lleva a afirmar que la supervivencia del sistema de protección está vinculada a la asunción de reformas estructurales alejadas de un momento coyuntural concreto: que sean fruto de debate y consenso y que estén integradas en un plan meditado y de largo alcance, lejos de la improvisación.

4. Nuestro sistema de protección social de nivel contributivo está lo suficientemente consolidado. Sin embargo, las prestaciones de carácter asistencial, financiadas con impuestos, son más débiles y se corre el riesgo de cronificar la pobreza en sectores más vulnerables a las crisis económicas. Como ya advertía el RDL 20/2020, es necesario y urgente racionalizar las prestaciones asistenciales más allá de la relación Ingreso Mínimo Vital/Prestaciones familiares con el fin de evitar duplicidades que produzcan una sobrecarga financiera al sistema.

5. Las transformaciones económicas, demográficas y sociales han aumentado con la crisis sanitaria. Los problemas clásicos del Sistema de Seguridad Social (envejecimiento de la población, nuevas formas de trabajo, revolución tecnológica, globalización...) están mutando como consecuencia de estas transformaciones. Los Gobiernos deben estar a la altura de la situación y prepararse para la reinvención del Estado de Bienestar en una era post-pandémica.

\section{Bibliografía}

AIRef (2019). Los programas de Rentas Minimas en España. Madrid AIRef. Disponible en https://www.airef.es (accedido: 21-10-2021).

Álvarez Alonso, Diego (2021). Contingencias y prestaciones de Seguridad Social en la Jurisprudencia del Tribunal Supremo. Madrid: Reus, p. 78.

Aragón Gómez, Cristina (2020). "El COVID-19 como riesgo causante de prestaciones de Seguridad Social», en Rodríguez-Piñero y Bravo-Ferrer, Miguel y Casas Baamonde, M. ${ }^{a}$ Emilia (dirs.): Derecho del Trabajo y de la Seguridad Social ante la pandemia, Madrid: Francis Lefebvre, 289-320. 
Arenas Gómez, Miguel (2020). «Prestaciones extraordinarias de Seguridad Social durante la situación COVID-19», IUSLabor, 2, 5-41. Disponible en: https://dialnet.unirioja. es/servlet/articulo?codigo=7537815 (accedido: 5-11-2021).

BAndrés Moliné, Eduardo (2012). «La Aritmética del Estado de Bienestar en España», Revista Ekonomiaz, 81, 38-61. Disponible en https://dialnet.unirioja.es/servlet/ articulo?codigo $=4080368$ (accedido: $21-10-2021$ ).

Barcelón Cobedo, Susana (2020). «Situación de necesidad económica y Seguridad Social: el ingreso mínimo vital como eje de la tutela», Labos: Revista de Derecho del Trabajo y Protección Social, 3, 172-183. Disponible en: https://e-revistas.uc3m.es/index. php/LABOS/article/view/5779 (accedido: 21-10-2021).

Beberidge, William (1942). Informe Beveridge o Beveridge Report. Título original: Social Insurance and Allied Services. Disponible en: https://www.parliament.uk/about/livingheritage/transformingsociety/livinglearning/coll-9-health1/coll-9-health/ (acedido: 21-10-2021).

Beltrán de Heredia Ruiz, Ignasi: «COVID-19 y medidas sociolaborales de emergencia», IUSLabor, 1, 45-110. Disponible en: https:/dialnet.unirioja.es/servlet/ articulo?codigo $=7484628$ (accedido: 5-11-2021).

Blasco Lahoz, José Francisco (2021). Seguridad Social y COVID-19. Valencia: Tirant lo Blanch.

Díaz Mordillo, María Alexandra (2020). «El Ingreso Mínimo Vital como reto social: una visión práctica", e-Revista Internacional de la Protección Social, 5, 35-59. Disponible en https://idus.us.es/handle/11441/105096 (accedido: 20-10-2021).

DíAz Mordillo, María Alexandra (2021). «La respuesta del sistema prestacional frente al reto COVID-19" e-Revista Internacional de la Protección Social, 6, 235-257. Disponible en https://idus.us.es/handle/11441/115983 (accedido: 16-10-2021).

Escolano, Román (2019). «Estado de bienestar y sociedad de bienestar», Fundación FAES. Cuadernos de pensamiento politico, 25-39. Disponible en https://dialnet.unirioja.es/servlet/articulo?codigo $=7129465$ (accedido: $21-10-2021$ ).

Farge Collazo, Carlos (2007). "El Estado de Bienestar», Enfoques XIX, 1/2, 45-54. Disponible en: https://dialnet.unirioja.es/servlet/articulo?codigo=3183498 (accedido: 21 10-2021).

Fernandez Avilés, José Antonio (2020). "Calificación jurídica de las contingencias derivadas del Covid-19 en el sistema español de Seguridad Social (navegando entre normas «ordinarias» y derecho "excepcional»)» Noticias Cielo, 4, 1-6. Disponible en: www.cielolaboral.com (accedido: 21-10-2021).

Gala Durán, Carolina (2020). «El nuevo ingreso mínimo vital estatal: régimen jurídico y retos pendientes" Revista sobre estudios sobre Ciencia del Trabajo y Protección Social, 1, 111-155. Disponible en: https://idus.us.es/handle/11441/103930 (accedido: 7-112021).

GonzÁlez Martínez, José Antonio (2020). «Medidas excepcionales en materia de Seguridad Social durante el COVID-19" e-Revista Internacional de la Protección Social, 5, 137-175. Disponible en https://revistascientificas.us.es/index.php/erips (acceso 2-112021).

Higuerillas Redecillas, Juan Carlos (2021). «Las pensiones en la Unión Europea. Análisis de los principales retos para la convergencia en una economía post COVID» $R e$ vista Universitaria Europea, 34, 161-188. Disponible en https://dialnet.unirioja.es/servlet/articulo?codigo=7851413 (accedido: 21-10-2021). 
Leguina, Joaquín (2014). "Envejecimiento y Estado del bienestar» Revista colegio Economistas de Madrid, 140, 24-32. Disponible en https:/dialnet.unirioja.es/servlet/ articulo?codigo $=4743395$ (accedido: 21-10-2021).

López Jiménez, José María (2011). «Estado de Bienestar, sostenibilidad y algunos riesgos», Extoicos, 1, 70-73. Disponible en https://dialnet.unirioja.es/servlet/ articulo?codigo $=4018757$ (accedido: 21-10-2021).

Luque Balbona, David y Guillén, Ana María (2021). "El recalibrado del gasto social público en España: ‘hacia un Estado orientado a la inversión social?», REIS: Revista Española de Investigaciones Sociológicas, 175, 85-104. Disponible en: https://dialnet. unirioja.es/servlet/articulo?codigo=7985837 (accedido: 21-10-2021).

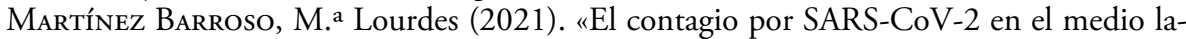
boral: entre el accidente de trabajo y la enfermedad profesional», Revista de Medicina de Familia Semergen, 47, 69-71. Disponible en: https://www.ncbi.nlm.nih.gov/pmc/ articles/PMC7980089/ (accedido: 9-11-2021).

Menéndez Sebastián, Eva María (2014). «Conclusiones e ideas sobre el Estado de Bienestar», DA, Nueva Época, 1, 100-101. Disponible en: https://vlex.es/vid/conclusionesideas-bienestar-541845726 (accedido: 21-10-2021).

Monereo Pérez, José Luís y Fernández Bernat, Juan Antonio (2021). «La opción por reformas paramétricas para garantizar las pensiones», en Hierro Hierro, Francisco Javier (dir.), Perspectivas Jurídicas y Económicas del Informe de Evaluación y Reforma del Pacto de Toledo de 2020. Madrid: Thomson Reuters Aranzadi, 49-84.

Monereo Pérez, José Luís (2020). «La Pandemia COVID-19 como «Hecho Social Total» y su impacto en el derecho social», en Ortiz Castillo, Francisco (Ed.), Derecho Vivo de la Seguridad Social. IV Seminario permanente de Estudio y actualización URJCAESSS 2019. Murcia: Laborum, 169-232.

Monereo Pérez, José Luis, Rodríguez Iniesta, Guillermo y Trillo García, Andrés Ramón (2020). El ingreso minimo vital en el sistema de protección social. Estudio de su configuración y Régimen jurídico. Murcia: Laborum.

Monereo Pérez, José Luís (2020). "La Renta Mínima Garantizada como medida estructural del Sistema de Seguridad Social en la Sociedad del Riesgo", Lex Social, 10, 424-505. Disponible en: https://www.upo.es/revistas/index.php/lex_social/article/ view/5074 (accedido: 7-11-2021).

Monereo Pérez, José Luís y Rodríguez Iniesta, Guillermo (2019). «Repensar críticamente el modelo de regulación de la pensión de jubilación», en Ortiz Castillo, Francisco (ed.), Por una pensión de jubilación adecuada, segura y sostenible. III Congreso Internacional y XVI Congreso Nacional de la Asociación Española de Salud y Seguridad Social. Murcia: Laborum, 21-90.

Monereo Pérez, José Luís (2017). La metamorfosis del Derecho del Trabajo, Albacete: Bomarzo.

Monereo Pérez, José Luís (2015). «Las reformas de las pensiones. Un análisis global del proceso reformista», en Monereo Pérez, José Luis (Dir.) y López Cumbre, Lourdes (Dir.), La Pensión de Jubilación. Estudio analitico y crítico tras los últimos procesos de reforma. Madrid: Comares, 1-58.

Moreno Fuentes, Francisco Javier (2007). «Inmigración y Estado de Bienestar en España" Revista Política y Sociedad, 44, 171-184. Disponible en https://dialnet.unirioja. es/servlet/articulo?codigo $=2524990$ (accedido: 21-10-2021).

Moreno Preciado, Manuel (2012). "Crisis, salud y bienestar ¿̇del Estado Social al Estado de Beneficencia?» Arch Memoria, 9, 1. Disponible en https://dialnet.unirioja.es/servlet/articulo?codigo=3897926 (accedido: 21-10-2021). 
Muñoz de Bustillo Llorente, Rafael y Grande Martín, Rafael (2017). «Inmigración y Estado de bienestar en Espańa" Anuario CIDOB de la Inmigración, 206-229,. Disponible en www.cidob.org (accedido: 21-10-2021).

Muñoz de Bustillo Llorente, Rafael (2019). Mitos y realidades del Estado de Bienestar. Madrid: Alianza.

OECD (Organización para la Cooperación y el Desarrollo económico) (2013) Government at a Glance 2013. Disponible en www.oecd.org (accedido: 21-10-2021).

PÉrez del Prado, Daniel (2020). "Un primer análisis ante el nacimiento de una nueva prestación: el ingreso mínimo vital», en Casas Baamonde, M.a Emilia (dir.) y Rodríguez-Piñero Bravo-Ferrer, Miguel (dir.), Derecho del trabajo y de la Seguridad Social ante la pandemia, Madrid: Francis Lefebvre.

Plan de Acción del Pilar Europeo de Derechos Sociales, disponible en https:// ec.europa.eu/info/strategy/priorities-2019-2024/economy-works-people/jobs-growthand-investment/european-pillar-social-rights/european-pillar-social-rights-actionplan_es (accedido: 16-10-2021).

Pons Pons, Jerónima y Vilar Rodríguez, Margarita (2020). La gestión del seguro de accidentes del trabajo en España: de Mutuas Patronales a Entidades Colaboradoras de la Seguridad Social. 1900-2019, Madrid: MIC.

Rodríguez Guerra, Jorge (2006). «Globalización y Estado de Bienestar. ¿Por qué no ha sido desmantelado el Estado de Bienestar?» Revista Internacional de filosofía politica, 27, 147-167. Disponible en https://dialnet.unirioja.es/servlet/ articulo?codigo=2149118 (accedido: 21-10-2021).

SADA, Daniel (2001). «Una visión europea del estado de bienestar» Revista Colección Año VII, 11, 41-61. Disponible en: https://repositorio.uca.edu.ar/ handle/123456789/10127 (acceso 21-10-2021).

Sala Franco, Tomás y Martín-Pozuelo López, Ángela (2020). El Ingreso Minimo Vital. El Sistema Español de Rentas Minimas. Valencia: Tirant lo Blanch.

Subdirección General de Ordenación y Asistencia Jurídica del Instituto Nacional de la Seguridad Social (2018). El sistema español de la Seguridad Social. Antecedentes y Modelo Actual, Madrid: MEYSS.

Torres López, Juan (2010). «¿Es viable el Estado del bienestar en la globalización?»Gaceta Sindical. Reflexión y Debate. Nueva etapa número 15 Defensa y Proyección del Estado de Bienestar, 15. Disponible en https://n9.cl/s5tzs (accedido: 21-10-2021).

Tortosa, José Maria (2010). «Estado y Estado de Bienestar: coyuntura y perspectivas de futuro", Daimon-Revista Internacional de Filosofía, 51, 7-23. Disponible en https://revistas.um.es/daimon/article/view/148471/131841https://sid-inico.usal.es/legislacion/ ley-general-de-la-beneficencia-publica-y-privada-de-20-de-junio-de-1849/ (accedido: 21-10-2021). 